\title{
Bacillary angiomatosis in a human immunodeficiency virus negative patient: A rare case
}

\author{
Gaxa Luvo, Hlatshwayo Bafana
}

\begin{abstract}
Introduction: Although bacillary angiomatosis is generally known to be an opportunistic condition in immunosuppressed individuals there are extremely rare and exceptional occasions where it occurs in immunocompetent individuals. The incidence of bacillary angiomatosis in immunocompetent persons is not documented in the literature mainly due to the rarity of this condition in immunocompetent individuals. Routine histopathological evaluation helps in confirming the diagnosis of its varied presentations like infected lymphadenopathy, bone lesions, bacillary peliosis of the liver or the spleen as well as cutaneous bacillary angiomatosis. Giving four doses of 250-500 mg dose of erythromycin per day has proved to be the most successful treatment option and other antibiotics like Doxycycline $100 \mathrm{mg}$ twice a day and ciprofloxacin are also showing good results. Case Report: We report a retro viral disease negative in a seven-year-old girl who presented to us with a six-month history of bilateral neck fast growing masses. Birth history showed that the patient was delivered through a normal vaginal delivery with an uneventful birth history. The
\end{abstract}

Gaxa Luvo', Hlatshwayo Bafana²

Affiliations: ${ }^{1} \mathrm{MBChB}$, Senior Registrar, Diagnostic Radiology and Imaging, Polokwane-Mankweng Hospital Complex, Polokwane, Limpopo, South Africa; ${ }^{2}$ Dip Rad Diag, MBChB, MMed Rad D, Senior specialist, Diagnostic Radiology and Imaging, Polokwane-Mankweng Hospital Complex, Polokwane, Limpopo, South Africa.

Corresponding Author: Bafana Elliot Hlatshwayo, P.O. Box 571, Kwa-Xuma, Gauteng1868, South Africa; Ph: +27152875122; Fax: +27862600185; Email: hlatshwayo. bafana@gmail.com

Received: 17 March 2015

Accepted: 09 April 2015

Published: 10 August 2015 birth weight was $2.7 \mathrm{~kg}$ and the birth length was $46.5 \mathrm{~cm}$. The Apgar score was 10/10. The body weight at presentation was $22 \mathrm{~kg}$. The pulse 139/ min, respiratory rate $24 \mathrm{bpm}$, temperature $36.2^{\circ} \mathrm{C}$ and $100 \%$ saturation. The diagnosis of bacillary angiomatosis was made on clinical, radiological and histopathological findings. The patient was treated with antibiotics and there is reduction in the degree of neck swelling on patient's follow-up ever since the treatment was initiated. Conclusion: The diagnosis and the management of bacillary angiomatosis needs a teamwork of various specialists which includes but not limited to pediatric oncologists, radiologists and histopathologists. It is extremely uncommon to make a diagnosis of bacillary angiomatosis in HIV negative patients. There are no specific clinical or radiological features to confidently make a final diagnosis of bacillary angiomatosis and as a result biopsy has to always be performed to secure a final diagnosis.

Keywords: Bacillary angiomatosis, Human immunodeficiency virus, Lymphadenopathy, Negative

\section{How to cite this article}

Luvo G, Bafana H. Bacillary angiomatosis in a Human Immunodeficiency virus negative patient: A rare case. Case Rep Int 2015;4:22-25.

Article ID: 100011CRINTGL2015

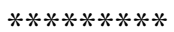

doi:10.5348/crint-2015-11-CR-6 


\section{INTRODUCTION}

Bacillary angiomatosis is an opportunistic potential fatal pseudoneoplastic infectious vascular proliferative disorder that primarily affects patients with Acquired Immunodeficiency disease (AIDS) most notable in the late stages of AIDS victims with CD4 lymphocytic count below 200 cells per cubic millimeter [1-3].

Two gram-negative bacilli from the genus Bartonella are well known and recognized organisms that cause bacillary angiomatosis in humans and these organisms are Bartonella henselae and Bartonella quintana [1].

Bartonella henselae is the pathologic agent of catscratch transmitted by fleas and clinically characterized by lymphadenopathy and skin or visceral lesions [3].

\section{CASE REPORT}

A seven-year-old female presented to us with a sixmonth history of bilateral neck fast growing masses. The patient's retroviral disease (RVD) status was negative on both ELISA and Western blot tests. The patient's mother tested negative on ELISA test. Birth history showed that the patient was delivered through a normal vaginal delivery with an uneventful birth history. The birth weight was $2.7 \mathrm{~kg}$ and the birth length was $46.5 \mathrm{~cm}$. The Apgar score was 10/10.

The patient had normal developmental milestones throughout her life and there was no known comorbidities.

The body weight of the patient at presentation was $22 \mathrm{~kg}$. The pulse $139 / \mathrm{min}$, respiratory rate $24 \mathrm{bpm}$, temperature $36.2^{\circ} \mathrm{C}$ and $100 \%$ saturation.

Blood results showed elevated neutrophils while the rest of the full blood count was within normal limits. Renal and the liver function tests were also grossly normal.

Computed tomography (CT) scan showed bilateral round to oval shaped neck lymphadenopathy involving all the neck spaces (Figures 1 and 2). Some of the enlarged lymph nodes were mattered. The lymph nodes were enhancing postcontrast. The differential diagnosis on CT scan included: 1. Tuberculosis, 2. Lymphoma, 3. Castleman's disease.

Biopsy was then performed and it confirmed the diagnosis of bacillary angiomatosis.

The histopathology results in our patient were as follows:

Microscopy section showed a lymph node dissected by fibrous septa and hyaline deposits. Postcapillary venules were prominent and marked vascular proliferation. The germinal centers are regressive and exhibit plasma cells. The profile showed strong positivity of WarthinStarry stain in keeping with the diagnosis of bacillary angiomatosis (Bartonella henselae).

The patient was treated with antibiotics which included imipenem $500 \mathrm{mg}$ IVI 6 hourly, isoniazide 200 $\mathrm{mg}$ p.o. daily. The patient was also put on bactrim 1 tab per os daily and on fluconazole $240 \mathrm{mg}$ intravenously daily. On follow-up the patient showed signs of improvement ever since the treatment was initiated a finding that is characterized by the reduction in the severity of the neck swelling

\section{DISCUSSION}

Bacillary angiomatosis is an opportunistic potential fatal pseudoneoplastic infectious vascular proliferative disorder that primarily affects patients with acquired immunodeficiency disease (AIDS) most notable in the late stages of AIDS victims with CD4 lymphocytic count below 200 cells per cubic millimeter [1-3].

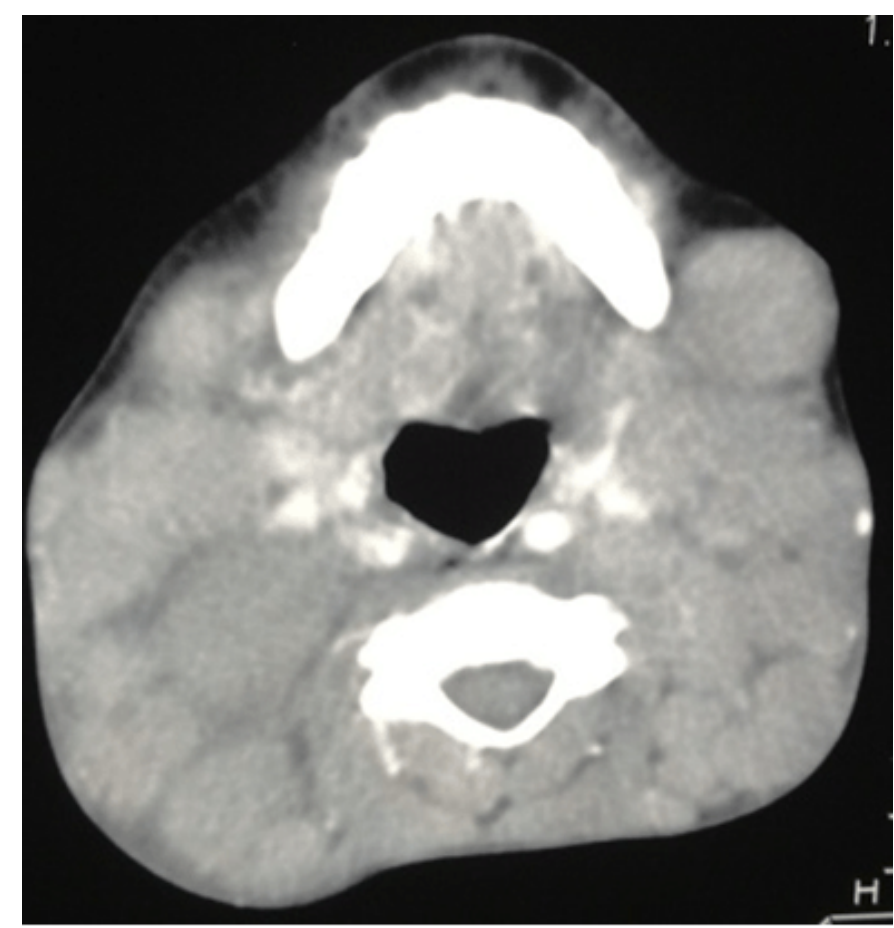

Figure 1: Computed tomography scan of neck (axial view) showing bilateral neck clustered lymphadenopathy displacing major vessels medially.

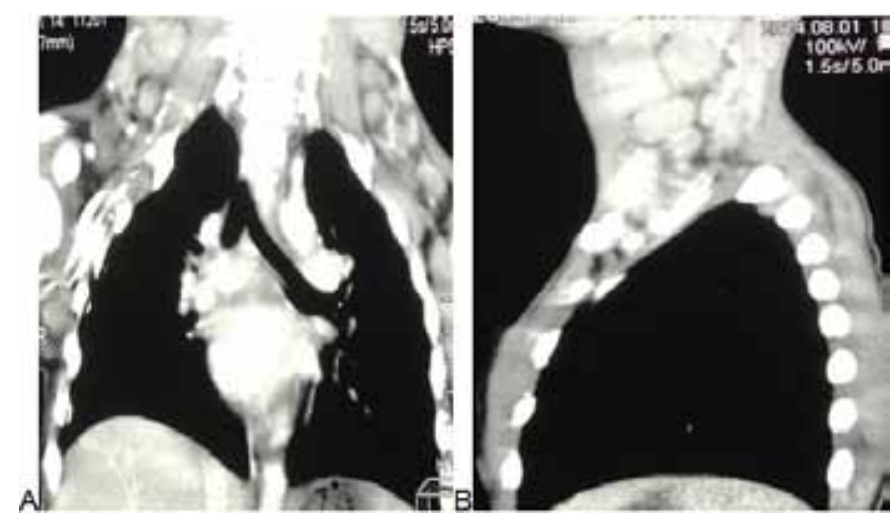

Figure 2: (A, B) Coronal and sagittal views of the chest and the lower neck confirming the presence of diffuse bilateral neck lymphadenopathy. 
Stoler et al. reported the first case of bacillary angiomatosis in a human immunodeficiency virus infected patient in year 1983 [3].

Other immunosuppressive conditions also predispose to the development of Bacillary angiomatosis, and these conditions include patients on long-term steroid therapy and organ transplant recipients and it is of importance noting that it is an extremely rare and an exceptional encounter do diagnose bacillary angiomatosis in immunocompetent individuals [1]. The HIV status of the patient was negative.

Bartonella quintana is now widely diagnosed in homeless people and the vector is a human body louse and was a cause of Trench fever during the First World War [3].

Bartonella henselae is not only limited to causing bacillary angiomatosis but has been noted as the causative organism in many other life-threatening disorders which include but not limited to neuroretinitis, encephalopathy, endocarditis, hepatic peliosis, hemolytic anemia and thrombocytopenic purpura [4].

Some of the risk factors of this opportunistic disease are socioeconomic status and a contact with cats [5].

There are two forms of mucocutaneous manifestations of bacillary angiomatosis are the popular and the nodular types. Popular type typically presents with lesions that are rubbery to firm, red to purple and elevated and as granulation tissue-like appearance with variable sizes ranging between one millimeter and several centimeters [6].

The nodular type lesions are diagnosed by palpation and lesions are tender and do not overly the skin although lesions that are larger may breakthrough to the surface [6].

Routine histopathological evaluation helps in confirming the diagnosis be it presenting as infected lymphadenopathy, bone lesions, bacillary peliosis of the liver or the spleen as well as cutaneous bacillary angiomatosis [6].

Giving four doses of 250-500 mg dose of erythromycin per day has proved to be the most successful treatment option and other antibiotics like doxycycline $100 \mathrm{mg}$ twice a day and ciprofloxacin are also showing good results [7].

One case of bacillary angiomatosis demonstrated a good response to dapsone $100 \mathrm{mg}$ per day and zidovudine $500 \mathrm{mg}$ per day [7].

\section{CONCLUSION}

Bacillary angiomatosis is an opportunistic condition commonly diagnosed in patients with AIDS. However, patients with other immunosuppressive disorders are also predisposing to bacillary angiomatosis. Diagnosing bacillary angiomatosis in immunocompetent individuals is extremely rare and exceptional. Histopathological diagnosis is the ultimate method.

\section{$* * * * * * * * *$}

\section{Acknowledgements}

We are thankful to our Radiographers Molopa Moyahabo Tink and Makuka Emilly Mogashoa for retrieving and preparing images for this case study.

\section{Author Contributions}

Luvo Gaxa - Substantial contributions to conception and design, acquisition of data, Analysis and interpretation of data, Drafting the article, Revising it critically for important intellectual content, Final approval of the version to be published

Bafana Elliot Hlatshwayo - Substantial contributions to conception and design, Revising it critically for important intellectual content, Final approval of the version to be published

\section{Guarantor}

The corresponding author is the guarantor of submission.

\section{Conflict of Interest}

Authors declare no conflict of interest.

\section{Copyright}

(C) 2015 Luvo Gaxa et al. This article is distributed under the terms of Creative Commons Attribution License which permits unrestricted use, distribution and reproduction in any medium provided the original author(s) and original publisher are properly credited. Please see the copyright policy on the journal website for more information.

\section{REFERENCES}

1. Long SR, Whitfeld MJ, Eades C, Koehler JE, Korn AP, Zaloudek CJ. Bacillary angiomatosis of the cervix and vulva in a patient with AIDS. Obstet Gynecol 1996 Oct;88(4 Pt 2):709-11.

2. Fagan WA, DeCamp NC, Kraus EW, Pulitzer DR. Widespread cutaneous bacillary angiomatosis and a large fungating mass in an HIV-positive man. J Am Acad Dermatol 1996 Aug;35(2 Pt 2):285-7.

3. Dardenne S, Coche E, Weynand B, Poncelet A, Zech F, De Meyer M. High suspicion of bacillary angiomatosis in a kidney transplant recipient: a difficult way to diagnose--case report. Transplant Proc 2007 JanFeb;39(1):311-3.

4. Bellissimo-Rodrigues F, da Fonseca BA, Martinez R. Bacillary angiomatosis in a pregnant woman. Int $\mathrm{J}$ Gynaecol Obstet. 2010 Oct;111(1):85-6.

5. Draganova-Tacheva RA, Domsky S, Paralkar V, Truant AL, Hurford M. Bacillary Angiomatosis as an Initial Presentation in an HIV-Positive Man. Clinical Microbiology Newsletter 2009;31(19): 150-2.

6. Manders SM. Bacillary angiomatosis. Clin Dermatol 1996 May-Jun;14(3):295-9.

7. Fernandez-Bussy RA, Alonso1 AB, Carlson D, Ramonda1 S, Salerni G, Reeves G. Bacillary angiomatosis in an HIV-positive patient. Good response to Dapsone. 1995;4(3):289-93. 
Access full text article on other devices

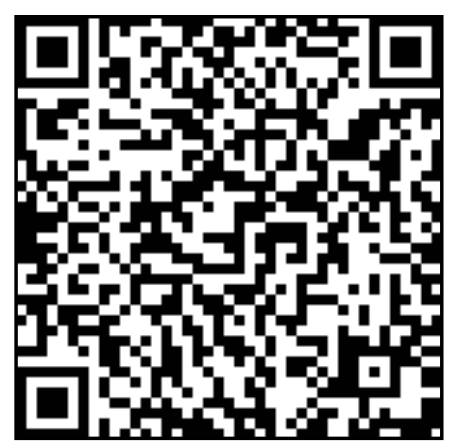

Access PDF of article on other devices

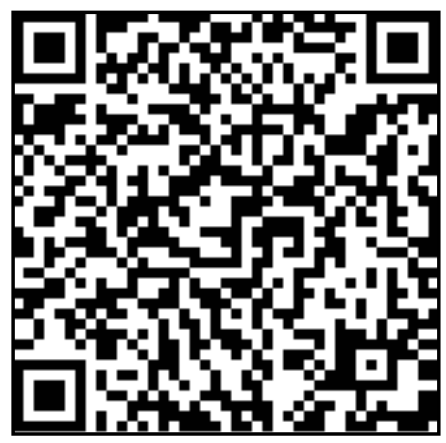

